\title{
I think there should be a mutual learning. Interview with Ezra S. Susser
}

\author{
Eu acho que deve haver uma aprendizagem \\ mútua. Entrevista com Ezra S. Susser \\ Creo que debe haber un aprendizaje mutuo. \\ Entrevista con Ezra S. Susser
}

doi: 10.1590/0102-311XEN011216

\author{
Marilia Sá Carvalho 1 \\ 1 Programa de Computação \\ Científica, Fundação Oswaldo \\ Cruz, Rio de Janeiro, Brasil. \\ Correspondence \\ M. S. Carvalho \\ Programa de Computação \\ Científica, Fundação \\ Oswaldo Cruz. \\ Av. Brasil 4365, Rio de Janeiro, $R J$ \\ 21040-360, Brasil. \\ mariliasaca@gmail.com
}

Ezra S. Susser, MD, DrPH, Professor of Epidemiology and Psychiatry, is the Director of the Psychiatric Epidemiology Training program at the Mailman School of Public Health, Columbia University (New York, USA). Most of his career has been dedicated to psychiatric epidemiology, in the United States and worldwide.

Among his extensive publications, the articles on causality and the future of epidemiology are important for all epidemiologists and were the main topic of this interview. Since he recently was on the Executive Committee that staged the Epidemiology Congress of the Americas 2016, he also shared with us his ideas on epidemiology in the Americas.

Professor Susser emphasized the exchange between Latin America and North America and its importance for the development of epidemiology and public health. He went on to discuss the theoretical challenges faced by epidemiologists today, from counterfactual to systems thinking, from individual to population health science.

And that was not all: Obamacare, insurance companies, and universal health coverage; mortality in Harlem; food industry regulation; Puerto Rico and Zika. His final message was: "I think there should be a mutual learning". 


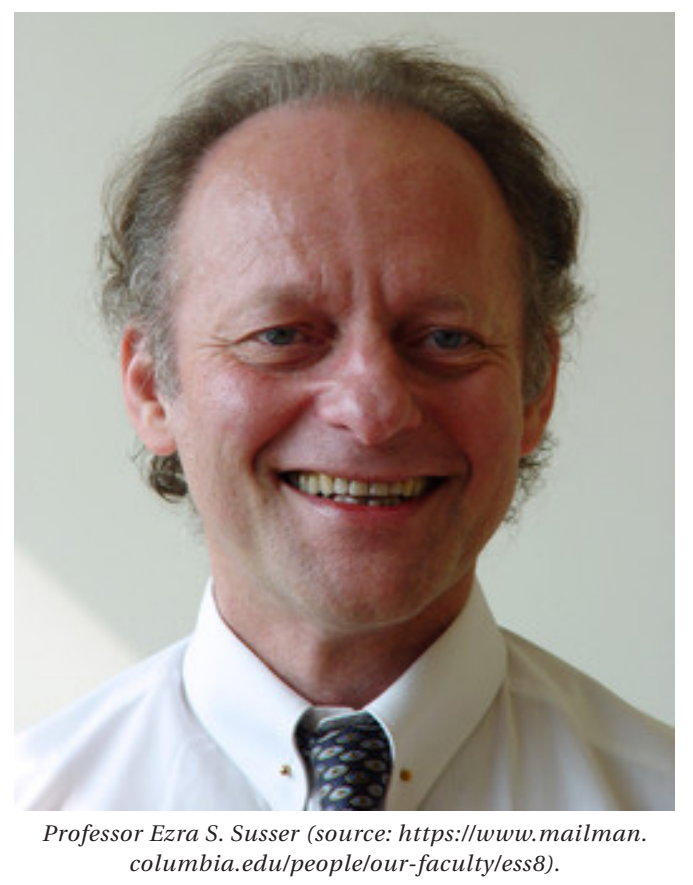

Carvalho I have two topics I would like to discuss with you about. First, let's talk about science cooperation, South-South, South-North, and the conference, the Epidemiology Congress of Americas 2016. Then, let's talk about the future of epidemiology. So let's begin with the first one. How was the conference and how was this experience with Brazilians and South Americans and so on.

Susser I think it was good. I think a key part was organizing the conference because it's always been a North American congress. There were some things that just happened to come together that enabled us to do it differently this time. One was that Jaime Miranda was the International Epidemiological Association (IEA) representative from Latin America and the Caribbean, and I was the representative from North America. The IEA had the ability to bring Latin America in by joining as one of the sponsors. Also, Sandro Galea was the head of the SER [Society for Epidemiology Research], which is not the only, but is the main organization in the US, the one that does more than anyone else, they do the most in organizing this conference, which is every five years. And then finally Cesar Victora was, at that time, president...

Carvalho President of the IEA.

Susser So for all of these reasons, at the time the decision was being made, we were able to propose that the IEA would be a full sponsor, which meant that Latin America would be in- cluded. And we were also able to get the other organizations on board, and Sandro [Galea] helped there, but they didn't really object, as long as IEA was willing to put their donation in, which hadn't been true in the past. So just having it was a big first step.

Carvalho And what did you think about this mixing of groups...

Susser I thought it was a great first start. We were able to provide some fellowships for people, especially for those coming from lowincome countries in Latin America. Funding was an issue. We had the Congress in Miami to make it easier, compared to other locations in North America. Cesar [Victora] had actually wanted it to be in Latin America, but we could never have got that through the North American groups this time. And about one third of the people who attended were actually from Latin America or the Caribbean, which is a lot. They'd never had that kind of attendance. We tried to give a lot of attention to it. There were several sessions that were organized by different groups from Latin America. And I think one of the most important aspects was that we had a group of young people from all over Latin America and from North America who met and formed connections with each other, across the continents and within Latin America. It also helped because the people didn't know each other beforehand - some did, some didn't - so it helped to form connections within Latin America, which is something that we've been 
working on for a long, long time, both Jaime [Miranda] and I in different ways.

Carvalho And how was the participation in terms of science? It's just an impression, what do you think about it? Because there are places.. Well, I know a bit about Brazil, of course, and about Argentina where I've given courses there, and Peru, and what was your feeling about the maturity of epidemiological research in Latin America?

Susser It depends [on] what you mean by maturity. There were good presentations, but... The thing about this conference is that it tends to emphasize methods a lot. And so, because of that, especially the kinds of methods, like methods that derive from or elaborate on counterfactuals and these kinds of things, which are not really areas... They're a little bit obscure to most people, and also maybe more to Latin America than to the US ones that now have been trained in that. It can be made to fit with the notion of eco epidemiology or collective health, but you have to work with it to make that happen. I don't think we were able to do that. We tried in the conference, I don't think we got too far with that. It's just the beginning, I thought.

Carvalho I understand perfectly. I myself am not very keen on counterfactuals.

Carvalho I'm much more into ecological studies, time series, spatial analysis, I'm much more a statistician than an epidemiologist, but closing the parentheses, when I ask about maturity, there is the side of methodological maturity and there is the side of questions, an ability to address real challenges.

Susser Well, I thought the people from Latin America and the Caribbean were better at that, they were better at defining the big questions, actually.

Carvalho In part because epidemiology, at least in Brazil, has never moved apart from public health, and that's a reason..

Susser And now they're trying, in the US; some people want to bring them back together.

Carvalho Especially the consequentionalist epidemiologists.

Susser Yes, especially...

Carvalho Consequentionalist epidemiologists, it's a very good paper.

Susser That's a way of saying it. People have been saying that for a long time, but it's now becoming more influential. I'm not sure if it's dominant yet, but it's becoming much more influential.

Carvalho Yes, I can see, that's what I've been doing these last months, reading, reading, reading. Straight from this point to the other point, I think there is a link...
Susser Well, a bit more on this point, Jaime [Miranda] and I, because I was working a lot in Latin America, although I was the US representative, we did a few things together. We're both involved in networks that priorize training a generation of people in Latin America who know each other across the countries as well as within the countries. There are so many bilateral relationships with the US because there's a lot of money in the US, but we're trying to help with this whole process.

Carvalho South-South cooperation.

Susser Yes, especially with the young people.

Susser I think better ideas or different ideas can come out of Latin America. There is a different tradition, and a long tradition, interrupted at times, but there's been a lot more thought about ecological studies or societal developments and the underlying factors that relate to health, as opposed to just differences between individuals. And I just think there could be a good balance. We need that, North American epidemiology needs that input.

Carvalho Going straight from what you said to the other topic, because it's absolutely linked, it's about the eco. It's not ecological studies, it's ecology for people, not ecology for animals, but for people. I have one question, I was reading, I'm in about the second or third chapter, this recent book by Sandro [Galea] and Katherine...

Susser By Katherine Keyes.

Carvalho Yes, Population Health Science, and they define population in two ways. One way is the population in a city, in a time, etc. The other way, population is a collection of people with similar characteristics, like a cohort of pregnant women, that's their example. What do you think about it?

Susser In general?

Carvalho Yes, because I have problems with this definition, that's why I'm asking you.

Susser Well, I don't have the book, Kerry [Keyes] is going to give me a copy, but I've read and heard them, and so forth. Here's what I think: I think that they encapsulate and explain some points quite nicely, that we're already quite aware of in epidemiology, but tend to overlook. One point they emphasize is the importance of not thinking that you should find the same thing in one population as another; another is the importance of looking at the underlying drivers of the health of the population, things like this. There may be points I don't really agree with, but I haven't yet read the book, just heard them talk about it.

Carvalho Neither have I finished it yet. I was very impressed with Epidemiology Matters and I loved The Macro Determinants of Health. But 
I asked this question because, for me, it's very difficult to fit all this counterfactual approach within the idea of ecology or within the idea of system science.

Susser It's very difficult, I don't think we're there yet, myself, that's the problem that I see. I think that we're struggling to get there but we're not really there, we haven't integrated them. That was the challenge for the last twenty years, so it's good that they're trying to take up that challenge, but I just don't think we have it yet. We have all this theory. The counterfactual stuff is based on, really, individual differences within a population. To take it to comparing populations... some people are trying... but it's not ready yet. System science is hard to apply, still. They're trying, and what I think they're trying to point out in some of these recent papers in AJPH [American Journal of Public Health], is to show that it can be applied, and to note applications, but it isn't yet a systematic theory of knowledge. The paradigm's not complete and that's been the problem all along

Carvalho That's my next question. Can you do that, or is it a shift in paradigm?

Susser [Pause] I'm thinking.

Carvalho I've told you, I'm much more a statistician, so my mind is much more related to modeling. System science is about feedback loops, non-linearizable relationships, and most regression models are useless, but you can fit it sometimes inside some specific topic.

Susser That's how I see it. You obviously know as much about this as me, I can tell, but the way I see it is that, of course, there are infinite number of levels of analysis, but individuals are important for disease, because obviously individuals get disease, individuals have to get disease, even if it's many individuals affecting each other, so that's an important level. But comparing individuals is just one way, one level that you can look at to understand causes of disease and prevention. And we're not always sure it's the most important level. And most of these theories are fit around assumptions that we're looking at individuals within a population and they have certain assumptions you have to violate, like they don't influence each other and all kinds of things like this. The most systematic models can't yet deal with reciprocity among causes; in practice they tend to break down when you introduce reciprocity. So you need a broader model that subsumes the current models and allows for the ways that the world actually works. I don't think you can do everything all the time, but people can place what they're doing within a broader model, that's what I think needs to happen. And people need to be aware of the other levels of influences that they're missing in their models, so they understand what they're not doing. That's how I see it, in general.

Carvalho I totally agree. I read a long time ago, and I've read recently, the idea of Chinese boxes. We call it the Babushka dolls. But even though this metaphor, it's not really about... because the Babushka is one inside the other.

Susser It's not always one inside the other.

Carvalho It's not always. I read recently in the newspaper, The Guardian, a story about tobacco and it's given me a very interesting insight. Everything we've done about tobacco, most things, are about the consumption side, the consumers. And we are fighting it all the time and people are getting addicted again and again. And so there is a medical doctor in Australia that decided to go to the financing side. It's wonderful, because that's another way, and if you have a systemic view, you might be better able to find other approaches. If you only look at individuals, you need to tell them not to smoke. But if you look at the society, you have to say "my insurance is paying the tobacco companies, why?" So I think that's ecology.

Susser I think tobacco is a good example, but there are many, many examples. But it's a good example. It's also good because it illustrates that there are two sides to the coin of government's role in health. Governments first played a role in getting people addicted to tobacco. When maufacturers started to be able to produce cigarettes on a mass scale, they had to figure out how to get everybody addicted to them, in order to sell very large amounts. As it turned out, they gave them to the soldiers in World War I and that whole generation of men became tobacco smokers. And then they did it again in World War II. The women between the wars who wanted to do the things men were doing started smoking too. Governments had a big role then, and still do in some countries. The Chinese government, for example, produces tobacco, and they make money off it, lots of money. So governments are not just benign. They can do a lot for health, but they aren't only promoting health. They sometimes help create the health problem. You have to advocate for governments to put in place things that will promote health, as opposed to damage health. Yet we've struggled so many years with changing individual behavior it's so difficult to do, and it's been the tobacco laws and the taxes that have actually been most effective, as you said. The bottom line is that it's another example of how political battles are one of the keys to promoting health.

Carvalho And what's the place of the health services or the health assistance system? Because I've been reading newspapers about how Obamacare doesn't improve anything. And it might be 
true, but I would like you to put it inside this idea of epidemiology doing something about...

Susser Well, it does a bit for public health intervention, not that much, but you can cover some preventive services which you couldn't before. It's really designed for individual health care, not for whole communities or societies, it doesn't really address that. It came out of a compromise with the insurance companies. Instead of having universal health care, which is really what we need, they extended a certain kind of universal health care to a larger number of poor people. "Medicaid" was extended from including only those who are very poor to including those who are at the next level of poverty, that is, they raised the income level at which you can get Medicaid. But for everyone else, it's very complicated. It's evolving, we don't really know how it's going to work. And a lot of people now are required to buy insurance (it's mandatory now to buy it) and don't like what they are getting. For example, a lot of young people don't like it because they have to buy insurance that is very expensive for them, and has huge deductibles. High deductibles mean that they have to spend a lot of money before the insurance ever kicks in. Usually young people don't have any major illness, but if they get an illness, they have to spend a lot before they get any help from their insurance plan. So it has lots of problems, and as it's evolving the insurance companies are getting stricter, I think, with the plans, and sometimes raising the cost. It's hard to document these things, but in general they're getting stricter in terms of what they will or won't cover. I think it was all Obama could do, given the Republican opposition, but I think it needs to go further for it to really work.

Carvalho But what are the...

Susser How will it affect health?

Carvalho No, what are the forces against, not in the political setting, but the main forces...

Susser I think it was the insurance companies who played the most fundamental role in preventing universal health coverage. They've inserted themselves in-between the person and the person's health care. Otherwise they'd be out of business. There are a few important exceptions. Medicaid is for people with low incomes and doesn't use insurance companies, not much anyway, only for special things, which is why it has helped some of the poorest people quite a lot. Also, Medicare for the elderly is mainly government run and it works quite well. I think there's where the problem is. The insurance companies are very, very profitable, they're huge. And that was the compromise that Obama made with them; most people would still get their coverage by buying it from insurance companies. The Clintons couldn't get a health care bill passed in the 90s, largely because the insurance companies opposed it and they were too powerful. Marcia Angell used to be editor of the New England Journal of Medicine, and she's also a well-known writer, and her view was that without having at least the "public option" - which meant you could choose to have government coverage (similar to Medicare) if you wanted - it wasn't worth passing it, it wasn't worth doing it. I didn't really agree with that, because I thought you had to take some step forward, but what Obama did is still not nearly enough. It's not enough to make much of a difference, I think, for most people. It does help that group of low-income people who have gained access to coverage by Medicaid, and does some other important things, such as making sure that people who already have an illness can buy insurance (which they usually could not do before the new health care legislation).

Carvalho I was reading about... mortality in the US has increased, general mortality, last year. Inequality? What's the reason?

Susser I honestly don't know the reason. But the US has a terrible health profile, compared to other wealthy countries, so why is this the case? It's partly to do with health care, but also with inequality and social conditions. It probably has more to do with that.

Carvalho And blaming the individual.

\section{Susser Yes.}

Carvalho I'm living in Harlem and you look in the streets and you see people with problems.

Susser And it's nothing like it used to be. Harlem now is gentrified.

Carvalho Totally. Totally no, partially.

Susser Yes, partially.

Carvalho You still meet lots of people who are homeless.

Susser Yes, but it used to be so poor, so... It's not just material poverty, they were so marginalized.

Carvalho Like favelas in Rio.

Susser Yes, the mortality rate was higher than in Bangladesh, that was a famous study that came out in the nineties.

\section{Carvalho Really?}

Susser Yes, your life expectancy beyond three years, I think, was less than in Bangladesh. More infant mortality in Bangladesh, but, after that... It's a famous paper by McCord and Freeman that was in the New England Journal of Medicine. It was one of the papers that influenced the thinking that it's not enough to tell individuals to change their behavior. More recently, Lee Goldman, the Dean of the Health Sciences in the Medical School at Columbia University, wrote a book about evolution and health. The main point 
he's trying to make is that we evolved in completely different conditions, so it's not going to work to just tell individuals not to do things that they already have a natural inclination to do, like wanting salts and sugars, maybe tobacco, drink, etc. It's partly socially patterned, but it's also patterned by evolution, so he feels that you can't do anything about it by telling individuals to do this, do that, that will never be enough. You have to actually change the social conditions so that people have the incentives and the environment that encourages them to do things differently.

Carvalho It's like "stop smoking”. My generation used to smoke, I used to smoke, and we all stopped more or less at the same time because it was becoming a bad thing. Not because of health, I knew it already, but because of the social environment.

Susser But then it shifted down to the poorer classes, smoking more, and then you have the taxes, so they then are paying taxes. All that stuff also happens.

Carvalho Even then, there are some observations on the streets that I've noticed, obesity among kids in Harlem seems to be less than in adults. Maybe there is already some consciousness about the problem.

Susser I'm not sure. It keeps changing.

Carvalho Yes, I know, it's optimistic.

Susser One time a report came out that, it looked like, in the very young kids, two to threeyear-olds, obesity was down. It was only two years and then from the next set of results, it seemed... We couldn't tell what's happening. But if you look at kids eight to fifteen, it's obesity is very high, among that group.

Carvalho Not as high as I expected, because I work a lot in the favelas in Rio and we have more obesity - just looking, no data, just observation - and we have more obesity in the kids from five to nine, five to fifteen, than I've seen in the streets here. And now it's the holidays, I go to the parks, maybe the kids who are overweight, they are at home.

Susser And New York's maybe a bit different.

Carvalho Not in the adults. The kids, maybe.

Susser I think the national data don't show much improvement, actually, and it's so high already that even if it just stays there... It doesn't mean it can't be improved, and that's what they're trying to do, that's one of the areas, it's trying to change access to healthier food, but it's got a long way to go.

Carvalho But there is something interesting as well on the guidelines for healthy eating, all these ideas of cultural... I think that's an area a systemic approach in essential. If you try to be in control all the time, you fail.
Susser I completely agree.

Carvalho And you cannot stop eating like you stop smoking. Some other approach is really essential. Including telling the industry not to put so many additives inside the snacks.

Susser And not such large portions.

Carvalho Not such large amounts, not so much sugar and corn syrup.

Susser So it's partly industry regulation, but I think it's also something they've known for ages. The Weight Watchers group have promoted this kind of approach, or you can promote the Mediterranean diet, but the whole idea is to eat a diet you can live with, a balanced diet you can live with so you're not hungry. The usual methods of dieting are not helpful... that's the problem, almost everybody's on a diet and that's not the way.

Carvalho It doesn't work.

Susser What has happened, is that there's a huge diet industry, it's enormous.

Carvalho All diets work for a short time.

Susser Yes, exactly, and we don't even know that that's good, to lose weight and then gain again. Seems that we agree about a lot of things, I'm not sure whether we disagree, we have a similar view.

Carvalho Let me confess that I loved your papers, but the papers I most loved were the four papers on ecological studies in the nineties. I use them in my courses. And Geoffrey Rose. Those are my favorite papers ever. It's very good to be talking with you.

Susser Well, it's nice. I think Rose is great, and that he is right up to a point. But I don't think you can just look at population averages. He may not really have wanted to be interpreted like. There are diseases that are not just the end of the population distribution. Not every disease is a continuum and it's not always best to shift the whole population, that's not always the way to go. You have to consider in each case what is the right level.

Carvalho As long as you have the larger picture.

Susser Yes, you've got to have the big picture in front of you.

Carvalho Because otherwise you get lost inside...

Susser Absolutely. And the details of analysis, the regression equations, when all the time what you're saying is true, you have reciprocal relationships, and other levels, and you don't grasp it, you can miss the forest for the trees, that's the trouble.

Carvalho That's the idea. And at Cadernos de Saúde Pública, I'm Editor-in-Chief together with Cláudia [Medina Coeli] and now Luciana [Dias de Lima] and we've written an Editorial that we 
called More of the Same Epidemiology. My feeling is that quite often epidemiology goes to repeat, repeat, repeat. It's linked with "publish or perish" and in our journal we see it quite a lot, so I joke saying I don't want to again discuss the prevalence of cigarette smoking. So how difficult is it to escape from this pressure, to publish numbers and think and be able to something like I think what science is?

Susser It's been difficult, it's been a while...

Carvalho And related with teaching students.

Susser I think it's going to take time and I think it does begin with the training, but the training is not there yet. I think every one gives lip service now, will say something about multi-level causation and this kind of thing, but the heart of training is still based on comparing individuals within populations. I think that's why it's important that Kerry and Sandro wrote that book, because there are things that we actually know but we just always overlook and that's important for student training, for people to internalize those things in training. So I think that's one way. But I think we also need methodologists who can address these issues. The leading methodologists in epi are not yet doing it and may need to combine more, perhaps, with econometrists, I don't know if they're the right people, but people who do that kind of thing.

Carvalho But ecologists.

Susser Ecologists, yes.

Carvalho They have such an interesting approach to problems and I think we need to learn more about it.

Susser Ecologists have the whole thing.

Carvalho They don't have the methods, they don't have the theory really evolved, they are much more into sample, catch...

Susser But they have the understanding.

Carvalho They have the understanding, a deep understanding. And demographers.

Susser Right, demographers too.

Carvalho Because they see the whole picture.

Susser I'm with you. When I was the Chair, I tried to bring demographers in and also a lot of interactions with ecologists and I do think those are two groups [who are] really important.

Carvalho I know you've made a big change in the courses, in the Master's courses. What are your feelings?

Susser Well, I'm not so much involved in that. I can't really say how well it's working, I don't know. You get different opinions about that. I think it was a good attempt. I like the idea of trying to integrate the different topics like biostat and epi, and trying to integrate thinking about the life course, and about systems, into public health training. I just don't know how well it's actually working in practice.

Carvalho We are trying to make some changes in the postgrad course in the National School of Public Health in Rio. Let's try it, it's difficult, but we need to do that.

Susser And they did, it's good to think it through. They did try to do that. What are the most important things to know? I don't know how well that turned out, I can't say.

Carvalho I don't know if you have something else you want to say, I'm happy.

Susser It's just nice to meet you, there's not that many people that you can have these conversations with, even though you can read a lot of people who think like this. At Columbia we sometimes start to imagine that everybody thinks like this, because this is the place where we've been doing it for so long, but if you go to different places, other schools around the country, you won't find the same acceptance of this way of looking at things. So it's nice to meet you. Also, I think Brazil was a big influence on this. Naomar [de Almeida Filho] held that crucial Brazilian conference in Bahia in the 90s. And you don't call it schools of public health, you call it saúde coletiva. And some of the other Latin American countries also have a tradition of this kind and I think that's been an influence here, or a help, anyway.

Carvalho Well, I just hope we can link more in equal terms.

Susser Well, that's what I would like to see.

Carvalho That's what I would like to see as well. I've been involved a bit with zika. Well, when I arrived, it was the peak of the epidemic in Brazil and I have some experience with dengue, modeling, always, collecting data is not exactly what I do, and I've been around in a few places, people ask me "Can you talk a bit about what's going on there?" And I've had really good experiences, in Michigan it was great, there were some places where I felt really annoyed, [I felt] condescension, but I think it was an exception, because in general people were like "You've done a very good job on this problem, let's do it together" and it was really pleasant. Exceptions made me just see how far we went.

Susser What do you think about the advisories? The advice the $\mathrm{WHO}$ and the $\mathrm{CDC}$ give. I find it completely ludicrous.

Carvalho Don't get pregnant. It's ridiculous. Susser I just can't grasp it. It's ridiculous.

Carvalho Half of the women in Brazil do not plan pregnancies.

Susser I'm glad you said that because I was a little nervous to say it, but... It's incomprehensible to me that they would... Even if you are planning 
it, who's going to do that? People have babies for all kinds of reasons.

Susser What do you think about Puerto Rico? Why is this happening? I find it interesting that it's still kind of a colony and I can't imagine that they would be so complacent about it, not exactly complacent, but they would have done much more if Puerto Rico was an actual state.

Carvalho I don't know why specifically Puerto Rico had such a...

Susser Apparently, it's partly distrust, because we used to test chemicals in Puerto Rico, so it partly is a problem of the population's perception of the federal health authorities. But it's also the federal health authorities, the efforts to overcome that. People don't see them as the same as US citizens, although they are, so it's an interesting situation, it's partly colonial. Perhaps it is a colony, actually.

Carvalho I was reading about this guy that's still in prison.

Susser Yes, there was an independence movement that was obliterated.

Carvalho Ten years ago.

Susser Yes. I won't distract you with that, it's just something that happened.

Carvalho No, I'm curious as well, I don't know. Again, we need to understand the specificities of each place, which is why it's difficult to think. Anyway, lots of challenges in public health. Transmissible diseases are back.

Susser Yes, it's back. There's something that I didn't really understand, so you would feel that they were right to let the Olympic games go on, because you think it's past the peak, because I was worried about it. I thought, everybody's coming from around the world, won't they take it back to other [places], I was thinking about that, sexual transmission, so many will come to Rio.

Carvalho First of all, you have to have lots of cases locally to be able to spread to the visitors. We don't have lots of cases now. We did have, in Rio, in January, February, not now. Second, tourists stay in the best places, not much risk. Third...

Susser But there are the prostitutes, that's a big issue.

Carvalho Yes, but the window of transmissibility is small and we don't have an epidemic now.

Susser I wasn't as sanguine, I thought it was risky, but I understand better now.

Carvalho I don't think it's risky now.

Carvalho Do you want to make a final...

Susser A final statement? I think the final statement would be more what I said before, I'd be repeating it. I think there should be a mutual learning. I think that there are things that, in Latin America in particular, in the tradition of public health there, that we need to make part of the tradition here, which we haven't yet done. And so, my feeling is that it's important to build the links among Latin American countries, but I think North America has to learn a lot from South America and that's difficult to do unless you have venues and ways to build that institutionally. Maybe I'll stop there.

Carvalho Thank you very much.

Susser It was lovely to talk to you.

Submitted on $01 /$ Nov/2016

Approved on 16/Nov/2016 